\title{
Poliomielite e seus efeitos tardios: viver ao ritmo da doença
}

Teresa Ventura*

\section{RESUMO}

Introdução: Muitos sobreviventes da poliomielite, após período de estabilidade clínica, desenvolvem complicações relacionadas com a doença. Este caso demonstra a necessidade do médico de família familiarizar-se com as múltiplas vertentes das repercussões tardias da poliomielite e reconhecê-las como entidade nosológica.

Descrição do caso: Doente, 69 anos, apresenta sequelas de poliomielite. A narrativa de vida evidencia o quanto a luta pela superação da deficiência foi central na sua trajetória. Inicia, décadas após a doença aguda, queixas progressivas de fraqueza muscular, fadiga, mialgias, poliartralgias, parestesias das mãos e depressão, condicionando incapacidade funcional crescente, bem como intolerância ao frio, incontinência urinária e perturbação do sono, por vezes associada a fasciculações. O exame objetivo e exames auxiliares de diagnóstico evidenciam lesão neurogénea crónica nos membros inferiores, síndroma do túnel cárpico e diversas doenças músculoesqueléticas. Face a novos sintomas, velhos sentimentos relacionados com a deficiência, que a própria julgava ultrapassados, são despertados.

O plano terapêutico envolve uma equipa multidisciplinar e inclui intervenções que incidem sobre: controlo dos sintomas e da evolução da doença; tratamento da psicopatologia coexistente; promoção de estilos de vida salutogénicos; adaptação da habitação e prescrição de ajudas técnicas; combate ao isolamento; mobilização de recursos informais, de serviços de saúde e sociais; transmissão de informação sobre a doença e problemas com ela relacionados.

Comentário: Os efeitos tardios da poliomielite podem ser minimizados nos seus sintomas mediante determinadas orientações. A sua gestão efetiva exige um olhar plural e holístico, cabendo ao médico de família identificar o cluster de sinais e sintomas presentes, bem como as suas repercussões psicossociais e, consoante estes, definir um plano terapêutico individualizado.

Palavras-chave: Síndroma Pós-poliomielite; Impacto Psicossocial; Médico de Família.

\section{INTRODUÇÃO}

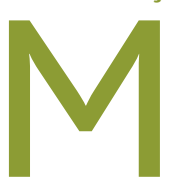

uitos sobreviventes de poliomielite desenvolvem, após um período de estabilidade clínica, complicações relacionadas com o antecedente comum. Consideramse complicações tardias da poliomielite as doenças músculoesqueléticas decorrentes do sobreuso das articulações e dos problemas de locomoção e a síndroma pós-poliomielite (SPP), resultante de nova deterioração neuronal motora anos após a doença aguda. ${ }^{1-4} \mathrm{~A}$ SPP caracteriza-se por fraqueza, fadiga e novas atrofias musculares, com ou sem dor, atingindo sobretudo a musculatura total ou parcialmente recuperada ou, me-

*Assistente graduada sénior, Unidade de Saúde Familiar Santo Condestável. Assis tente convidada, Faculdade de Ciências Médicas da Universidade Nova de Lisboa nos frequentemente, músculos clinicamente não afetados pela doença original. ${ }^{1-4}$ São, ainda, sintomas descritos nestes doentes: disfagia, disfunção respiratória, alterações da fala, intolerância ao frio, perturbações do sono, fasciculações, incontinência de esfíncteres, perturbações ansiosas e depressivas. ${ }^{3}$

Embora crónicos, os efeitos tardios da poliomielite podem ser minimizados nos seus sintomas, mediante determinadas orientações. No entanto, enquanto entidade, é insuficientemente (re)conhecida pela generalidade dos médicos, o que limita a sua intervenção.

Este caso pretende contribuir para a familiarização dos médicos com as múltiplas vertentes das repercussões tardias da poliomielite e descrever a intervenção do médico de família. 


\section{DESCRIÇÃO DO CASO}

\section{Dados demográficos}

Silvana [nome fictício], 69 anos, solteira, família unitária, concluiu a $4 .^{\text {a }}$ classe durante um internamento hospitalar. Trabalhou como costureira, a partir dos 12 anos, tendo-se reformado aos 50 anos por incapacidade para o trabalho.

\section{Antecedentes pessoais relevantes}

Silvana contraiu poliomielite aos 9 meses de idade, apresentando paralisia flácida do membro inferior direito.

Aos 8 anos, na sequência de tuberculose pulmonar, foi admitida num hospital. O internamento prolongou-se por dois anos devido às sequelas de poliomielite submeteu-se a múltiplas cirurgias que lhe permitiram uma marcha claudicante, mas já sem necessidade de bloqueio do joelho direito com a mão, como até então.

Refere depressão, aos 18 anos, autoatribuída à vida de "sofrimentos e inseguranças" (sic) de então, tendo sido seguida em psiquiatria.

Aos 48 anos inicia novamente sintomas depressivos associados à deterioração do seu estado de saúde, mais tarde agravados pela morte da sobrinha em acidente.

Refere hábitos tabágicos, 32 UMA (Unidade Maço Ano) e ingestão de quatro cafés diários. Nega consumo de álcool.

\section{História psicossocial}

Os pais de Silvana tiveram dois filhos e separaram-se tinha ela 5 anos, tendo o pai ficado com a sua custódia.

O pai recasou 10 anos depois. Silvana descreve a relação com a madrasta como pouco afetuosa, embora cordial.

Com a mãe, Silvana manteve uma relação conflituosa, por esta não aceitar a relação de cooperação da filha com a madrasta e a sua deficiência. Desvalorizada sistematicamente pela progenitora, Silvana desculpa-a "pela vida difícil que teve" (sic) e porque "não era fácil lidar com uma filha com a minha doença" (sic). Após a morte do pai e da madrasta, a relação mãe-filha tornou-se afável, embora permaneça distante.

Silvana reconhece que as sequelas da poliomielite não foram apenas motoras: durante a infância e a adolescência sentiu constrangimento social e adotou compor- tamentos de evitação dos pares por se sentir "a coxa" (sic). Considerando não ser capaz de viver o que era próprio para a sua idade, infantilizava-se deliberadamente.

O acompanhamento psiquiátrico na juventude tê-la-á ajudado "a lidar com a doença e com outros assuntos" (sic). Com o casamento do irmão estabeleceu uma relação coesa com a cunhada e com a sobrinha, modificando a sua perceção acerca das suas aptidões sociais. No trabalho obteve reconhecimento, com efeitos positivos na autoestima. Passou a estabelecer bom contacto interpessoal e, para evitar o isolamento, a ser ativa na manutenção das relações com o irmão, cunhada, vizinhas, colegas de trabalho e empregados das lojas da sua rua, que frequentava assiduamente, quase sempre apenas para conversar. Assim, orgulhosa, refere ter superado uma limitação grave e conseguido uma vida "normal" (sic), não obstante ultimamente, com a deterioração da sua capacidade física, decorrente de novos sintomas, se verifique uma retração dos contactos sociais.

Após falecimento do pai e da madrasta, Silvana passou a viver só na casa da sua infância, um rés-do-chão que desemboca num pátio plano, não pavimentado.

Considera o falecimento da sobrinha uma perda de que nunca poderá recompor-se.

Respondeu às questões do Apgar Familiar focalizada no irmão e na cunhada. O resultado foi de 7 pontos, o que sugere a ausência de disfunções.

Aplicou-se o Círculo Familiar de Thrower e, na representação que Silvana fez das figuras familiares e de outros próximos significativos, ressaltam a ausência da mãe; a proximidade e a valorização da relação com o irmão; as relações com a cunhada e, embora um pouco mais distantes, com a comadre e com a sua amiga Gilda (figura 1). Considera-se satisfeita com a dimensão da sua rede social e com a qualidade das relações que mantém com os seus elementos mais significativos, sublinhando que se apoiam mutuamente, embora preservando o espaço individual de cada um. Admite, no entanto, que gostaria de estar geograficamente mais próxima das pessoas representadas, de forma a mais frequentemente sentir o conforto dessas relações. Questionada sobre a quem recorre em primeiro lugar quando necessita de apoio, Silvana respondeu que depende do que precisa - no caso de a ajuda ser de natureza instrumental é ao irmão que se dirige; se for de tipo emocional recorre à cunhada ou à Gilda; por último, se 


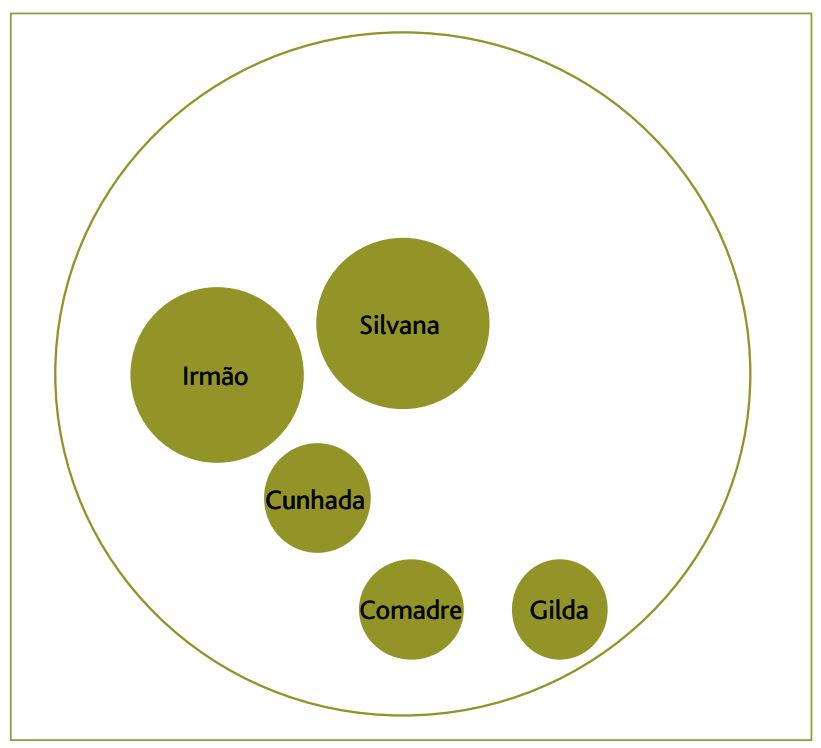

Figura 1. Círculo Familiar de Thrower.

o apoio for de natureza informativa fala com a comadre, que é "uma pessoa muito inteligente e sabedora" (sic). Quanto a eventuais ajudas de vizinhos, sabe que, se for mesmo necessário, poderá contar com eles, mas evita mobilizar esse recurso, pois "são pessoas com quem não simpatizo muito” (sic).

\section{História atual}

Após período de estabilidade clínica, cerca dos 45 anos, Silvana iniciou novas queixas, insidiosas, designadamente:

- Fraqueza e fadiga vespertina musculares, referidas sobretudo ao membro inferior direito, durante o exercício, poliartralgias, mialgias difusas e parestesias noturnas das mãos;

- Incontinência urinária;

- Perturbação do sono, com despertares frequentes, algumas vezes associados a fasciculações no membro inferior direito. Desconhecia se tinha apneia do sono, admitindo alguma sonolência diurna e negando cefaleias matinais;

- Tristeza, ansiedade, alterações da memória e da capacidade de concentração, fazendo antidepressivo, continuadamente, desde há cerca de 20 anos.

A progressão das queixas implicou dificuldades crescentes em diversas atividades, restringindo algumas delas (utilização de transportes públicos e a frequência de locais com acesso através de escadas) e descobrindo novos modos de realizar outras (exemplos: lavagem de louça com apoio, na bancada da cozinha, do antebraço do membro que segura cada peça; uso de canadianas para auxílio da deambulação e prevenção de quedas, ultimamente muito frequentes).

O uso de canadianas, como o de fraldas, por incontinência urinária, foi acompanhado por fortes sentimentos negativos, por atingirem a autoimagem e constituírem um sinal tangível da deterioração das suas condições físicas.

Refere intolerância ao frio, sobretudo na musculatura afetada, e a impossibilidade de manter o ambiente doméstico em temperaturas de conforto por limitações económicas.

Nega queixas respiratórias, disfagia, disfonia ou aumento de peso.

É acompanhada em consulta de reumatologia há vários anos, onde lhe foram prescritos hidroginástica em contexto hospitalar, para preservação muscular e alívio sintomático, terapêutica anti-inflamatória (aceclofenac) e antiosteoporótica (teriparatida, após resultados insatisfatórios com outros fármacos), com não adesão a esta última devido ao preço do fármaco prescrito e incapacidade financeira para $\mathrm{o}$ adquirir.

Teme o futuro, receando ficar confinada "a uma cadeira de rodas" (sic), tanto mais quanto sempre valorizou a sua autonomia e esta representou "a luta de uma vida” (sic). Este receio concretizou-se quando, há seis meses, na sequência de queda, fez fratura supra e intercondiliana do fémur direito, alinhada.

Tratada conservadoramente com aparelho gessado, em serviço de ortopedia, a alta hospitalar, adiada por motivos sociais, ocorreu após contratação de ajudante familiar pelos serviços sociais para acompanhamento domiciliário, após articulação das assistentes sociais das instituições de saúde dos níveis primário e secundário.

Após consolidação lenta, iniciou apoio ligeiro e progressivo com ortótese em extensão anca-joelho-tornozelo-pé e apoio em canadianas, assim como fisioterapia.

Por sugestão da própria doente, duplicou-se a dose de sertralina, agora $100 \mathrm{mg} /$ dia, dado sentir-se "em baixo" (sic) e necessitar de "força e ânimo para ultrapassar isto" (sic).

No exame físico salientam-se valores tensionais e um índice de massa corporal normais e as seguintes 
alterações: acuidade visual diminuída; marcha claudicante e uso de compensação ortopédica para dismetria dos membros inferiores; desvio lateral direito da coluna dorsolombar; inclinação pélvica; nos membros inferiores, arreflexia, atrofia e hipotonia à direita e atrofia do quadricípite na região distal da coxa e topografia baixa da rótula à esquerda.

Os resultados de testes analíticos e eletrocardiograma excluem algumas causas de fadiga, nomeadamente anemia, hipotiroidismo, diabetes mellitus, doenças renal, hepática e cardíaca.

Os radiogramas anteriores à fratura revelavam: osteopénia (figuras 2 e 3) com deformação somática de L1 e L3; espondilartrose com discartroses, anterolistesis de L4, escoliose dorsolombar e hiperlordose lombar (figura 2); artrose das articulações sacroilíacas à esquerda, atrofia da hemibacia e do fémur direitos, coxa vara (figura 3).

O eletromiograma sugere síndroma do túnel cárpico bilateral e, nos membros inferiores, lesão neurogénea crónica.

A osteodensitometria evidencia osteoporose.

\section{Plano}

Desde que há cerca de dois anos se inscreveu na lista da atual médica de família, Silvana tem tido, em média, 4 consultas anuais, ocorrendo estas no seu domicílio após fratura do fémur.

Silvana manterá fisioterapia enquanto se verificar potencial de recuperação da fratura do fémur, devendo ser incentivada a adotar boas práticas na prevenção das quedas, anteriormente já ensinadas. Como lhe foi recomendado, evita movimentos repetitivos e atividades físicas que se acompanhem de dor ou que, após dez minutos, provoquem fadiga, tendo adotado uma rotina diária que inclui períodos de repouso entre atividades do dia-a-dia. ${ }^{3}$ Deverá, ainda, manter o tratamento farmacológico, anti-inflamatório e antiosteoporótico, prescrito em reumatologia.

Importa manter a terapêutica farmacológica antidepressiva e continuar a propiciar à doente acolhimento e sustentação do sofrimento psíquico, embora estimulando-a a recordar tudo o que alcançou e não apenas as novas fraquezas. ${ }^{3}$

Recusou a prescrição de antidopaminérgicos para minimizar os movimentos involuntários dos membros, ${ }^{3}$ considerando que "para já não quero, estou a tomar muitos medicamentos" (sic).

A intolerância ao frio causa incomodidade e aumento da fadiga, pelo que a doente aprendeu a usar múltiplas camadas de roupa, luvas e meias, a fazer massagens de sentido distal/proximal e a aplicar calor nas extremidades, por curtos períodos de tempo, com recurso a botija de água quente. ${ }^{3}$

Requisitaram-se provas de função respiratória para detetar eventuais distúrbios que, embora mais comuns nos casos em que foi usada ventilação mecânica durante a poliomielite aguda, ${ }^{5}$ o que não ocorreu com Silvana, apresentam risco ampliado na população com SPP, comparativamente à população em geral. Neste caso, os hábitos tabágicos e a escoliose marcada da doente constituem-se como fatores contribuintes para o aparecimento desses problemas. Para excluir apneia do sono, de prevalência acrescida entre indivíduos com SPP, ${ }^{2,6}$ referenciou-se a doente a pneumologia para realização de polissonografia. Os resultados destes exames indicam doença pulmonar obstrutiva crónica (DPOC) leve (GOLD 1) $)^{7}$ e roncopatia, sem apneia, sendo que o pneumologista atribuiu esta última a desvio do septo nasal, pelo que referenciou Silvana a otorrinolaringologia para correção cirúrgica.

Referenciou-se a doente a oftalmologia, dada a diminuição da acuidade visual, tendo-lhe sido diagnosticada catarata do olho direito, aguardando marcação de cirurgia.

Dados os riscos de quedas, com consequentes ferimentos, e a DPOC, importa manter atualizada a vacinação antitetânica e antigripal, tendo já feito a antipneumocócica.

Silvana deverá moderar o consumo de café, atualmente excessivo, intensificador das fasciculações, do stress e das perturbações do sono. Refere ter tentado não o consumir, após conselho da médica de família, mas isso provocou-lhe cefaleia e sonolência, pelo que retomou o hábito. Então, negociou-se com a doente, não a sua interrupção abrupta, mas uma redução progressiva, bebendo agora três cafés diariamente.

Deverá manter o peso com uma dieta equilibrada e assegurar uma ingesta adequada de cálcio, evitando o agravamento da osteoporose, aspetos que já vinha tendo anteriormente em atenção.

Tem-se sensibilizado a doente para a cessação do tabagismo, que constitui um fator de agravamento da 


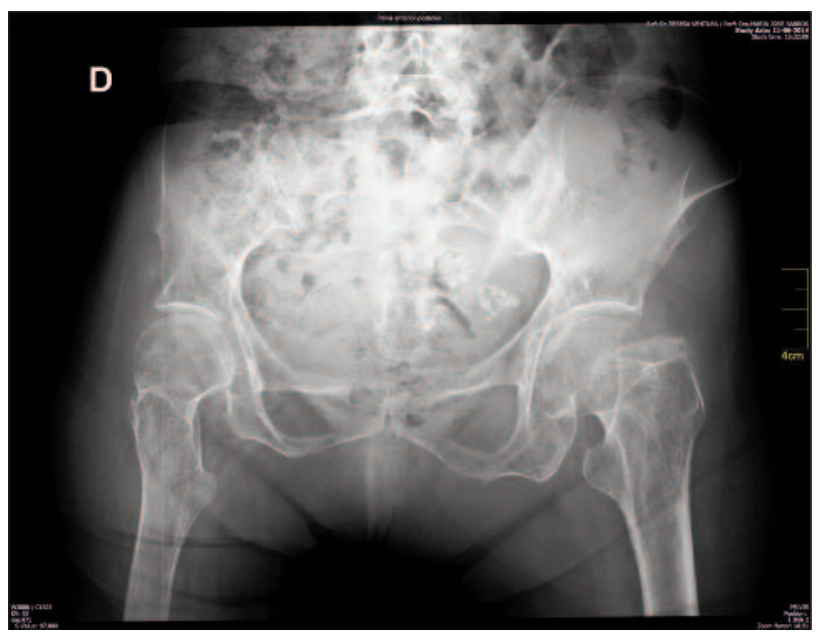

Figura 2. Radiograma da bacia.
Numa visita domiciliária conjunta com a assistente social e com a enfermeira de família identificaram-se e prescreveram-se os produtos de apoio indicados na situação de Silvana e, mesmo quando ainda era possível dispensá-los, incentivou-se o uso de suportes à locomoção, por favorecerem o equilíbrio, reduzirem o risco de quedas, promoverem uma melhor postura, aliviarem a carga sobre as articulações, minimizarem a fadiga e a energia requerida para a deambulação. ${ }^{3} \mathrm{~A}$ segurança do ambiente doméstico foi avaliada pela equipa, designadamente no que se relaciona com objetos, iluminação e piso da casa (tacos soltos), com subsequentes aconselhamento e mobilização de recursos, familiares e comunitários, para intervenções que reduzissem os riscos ambientais para quedas.

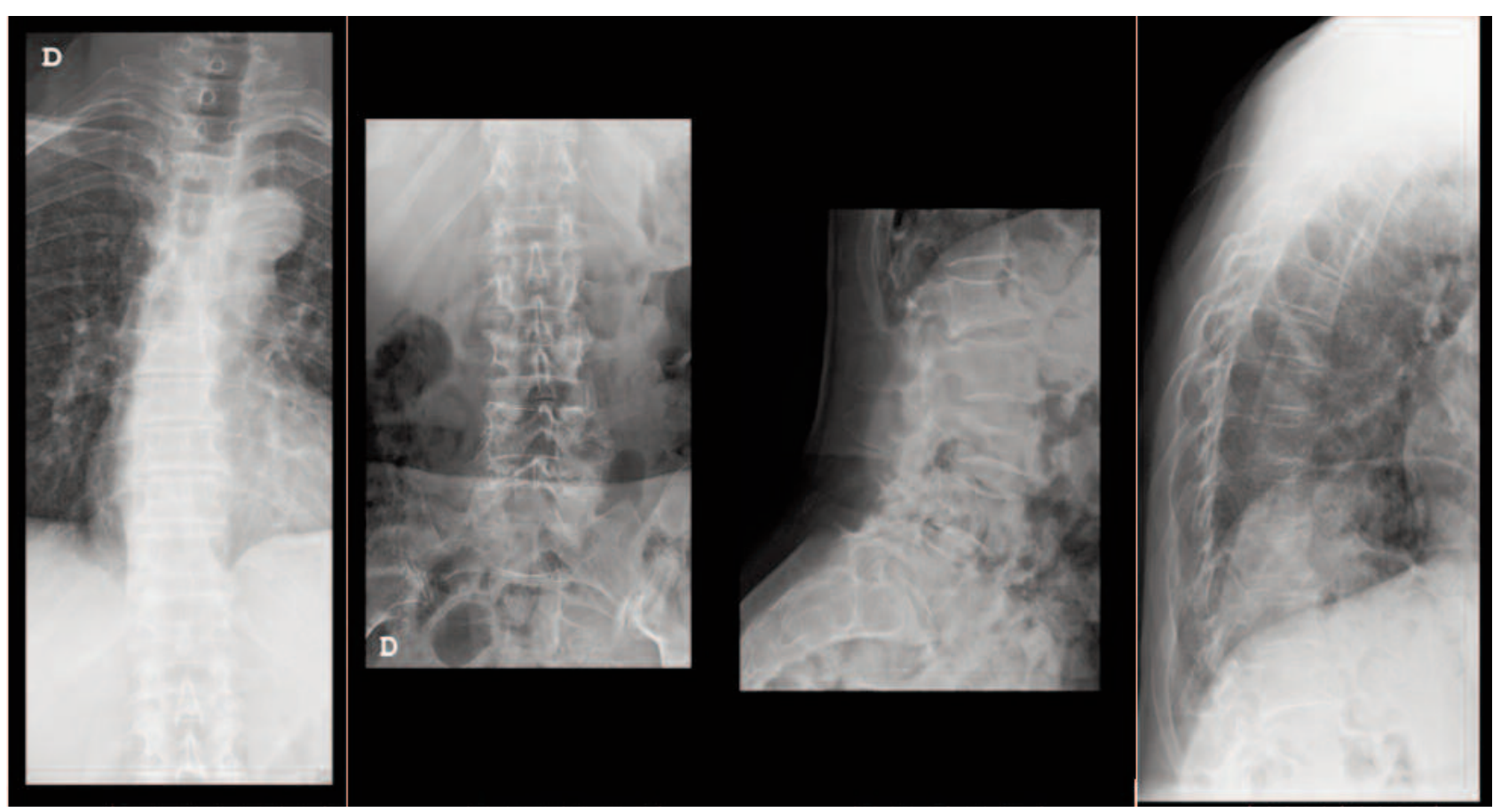

Figura 3. Radiograma da coluna dorsolombar.

fadiga e de risco para osteoporose e perturbações respiratórias, de incidência elevada na SPP, sendo que já apresenta DPOC. Não obstante Silvana evidenciar consciência dos benefícios que obteria com a cessação, rejeita a mudança do comportamento, alegando que o fumo lhe dá prazer, ajuda-a a lidar com circunstâncias difíceis, a reduzir a insegurança e a não engordar, motivos que têm vindo a ser tratados em consultas sucessivas.
É conhecido o ciclo vicioso de deterioração da saúde e rede social, presente no caso da Silvana. A restrição de mobilidade, mesmo antes do agravamento por fratura óssea, levou a doente a abandonar alguns dos locais que lhe eram habituais, conduzindo à limitação de contactos e ao enfraquecimento de vínculos. Assim, tem sido estimulada a cultivar relações sociais e a pedir ajuda quando necessário. 
A SPP exige vigilância contínua da sua evolução, da capacidade funcional da doente e da sua capacidade de gerir o quotidiano autonomamente, para mobilização de recursos clínicos e sociais de acordo com as necessidades em mudança. Assim, o seguimento de Silvana tem exigido multidisciplinaridade com várias referenciações, designadamente aos serviços sociais, por incapacidade financeira da doente para adaptar a casa à sua deficiência, adquirir a terapêutica antiosteoporótica prescrita e, após fratura do fémur, gerir o quotidiano autonomamente, tendo a assistente social mobilizado os recursos comunitários necessários à viabilização das soluções para esses problemas, mediante relatórios da médica de família e na sequência de visita domiciliária conjunta; à enfermeira de família, para ensino da administração subcutânea da teriparatida e, em visita domiciliária multidisciplinar, caraterização social; a pneumologia, para realização de polissonografia, cujo resultado determinou encaminhamento para otorrinolaringologia para correção da causa da roncopatia identificada; a oftalmologia, por catarata, favorecedora de quedas; a ortopedia, onde atualmente é seguida por fratura óssea, para cirurgia a síndroma do túnel cárpico; a fisiatria, para reabilitação após fratura e exercícios terapêuticos indicados nos efeitos tardios da poliomielite e, eventualmente, a psicologia clínica, de acordo com a evolução da depressão, que importa vigiar.

Dado a doente ter vindo a ser seguida como que em "ilhas separadas", para melhorar a concertação de medidas com a reumatologista, tomou-se a iniciativa de lhe escrever uma carta a partilhar informação.

Um nível elevado de informação sobre a doença e problemas com ela relacionados levará à perceção de maior controlo sobre a situação. Assim, diretamente ou através de outros profissionais da equipa multidisciplinar tem-se transmitido à doente informação sobre $a$ doença, a adaptação, aspetos de natureza instrumental, serviços disponíveis, subsídios e direitos.

\section{COMENTÁRIO}

Silvana tem critérios clínicos de SPP, mas, apesar do seguimento multidisciplinar, desconhecia a síndroma.

A doente apresenta alguns dos fatores apontados como preditivos de SPP, designadamente o género feminino, a existência de sequelas permanentes da poliomielite e o longo período de estabilidade clínica..$^{8-10}$ Não sabe precisar dados relativos a outros fatores, de- signadamente quadro motor inicial grave, intervalo longo entre o quadro agudo e o início da recuperação e grande recuperação. ${ }^{8-10}$ Este último fator tem sido explicado pela tendência dos doentes que o referem fazerem sobreuso da musculatura afetada e exercício físico excessivo para a sua condição. Outros fatores de risco estão ausentes, nomeadamente idade tardia na fase aguda da doença, ${ }^{8-9}$ hospitalização e ventiloterapia mecânica aquando da poliomielite aguda, ${ }^{5}$ idade avançada no início do quadro clínico de SPP, ${ }^{9}$ sobrepeso, ${ }^{8}$ dores musculares/articulares associadas ao exercício físico ou este ser intenso na fase de estabilidade clínica. ${ }^{9-10}$ A antiga profissão de costureira e a ausência de barreiras arquitetónicas na sua residência, excetuando a irregularidade do pavimento do pátio, protegeram a doente do exercício acentuado.

Nos casos de SPP, a experiência de sentir novos sintomas é geralmente devastadora, porque os doentes com sequelas de poliomielite costumam orgulhar-se de ter superado uma limitação grave, conseguindo uma vida igual à dos indivíduos saudáveis. Tal como Silvana, frequentemente escamoteiam limitações físicas e utilizam comportamentos compensatórios das suas desvantagens, mostrando-se perfeccionistas, zelosos no trabalho e ciosos da sua independência. A reação face à SPP é frequentemente de medo, angústia e confusão, assistindo-se ao despertar de velhos sentimentos relacionados com a deficiência, que os próprios julgavam ultrapassados, ou à negação da associação das queixas atuais com o antecedente de poliomielite. ${ }^{6}$

A maior prevalência de perturbações psiquiátricas, incluindo depressão e distress emocional, na população com história de poliomielite é contrariada por alguns estudos ${ }^{11-}$ ${ }^{12}$ e sugerida por outros, ${ }^{13-15}$ que a associam à vivência da poliomielite aguda, às dificuldades de afirmação social e à experiência de adoecer novamente. A depressão, quando presente como no caso de Silvana, poderá exacerbar a fadiga, a dor, as perturbações do sono e as incapacidades, importando monitorizar a sua evolução.

Até recentemente, Silvana nunca tinha recebido qualquer orientação sobre o tipo, intensidade e frequência do exercício físico a adotar. Em anos não longínquos, alguns profissionais associavam fadiga e fraqueza musculares à inatividade física e propunham exercícios vigorosos, incluindo a prática desportiva. No entanto, alguns estudos sugerem que, nesta população, a prática de exer- 
cícios de intensidade acentuada induz degeneração dos neurónios do corno anterior da medula., ${ }^{4,9,16-17}$

A gestão médica da SPP é dificultada pelo número, complexidade e diversidade de sintomas, associados à incerteza sobre a etiologia subjacente, à ausência de testes diagnósticos patognomónicos e de tratamentos curativos.

Apesar dos mecanismos fisiopatológicos da SPP serem incertos, existem diversas teorias que focam ${ }^{3-4,9,18}$ alterações degenerativas ou disfunção da unidade motora, derivadas do sobreuso ou do envelhecimento prematuro; o uso excessivo da musculatura; o desuso muscular; a predisposição para a degeneração do neurónio motor devida às alterações gliais, vasculares e linfáticas causadas pela poliomielite aguda; a infeção crónica pelo poliovírus ou reativação viral; a síndroma imunomediada; a diminuição da libertação da hormona de crescimento; e o efeito combinado do uso excessivo da musculatura, dor, aumento de peso ou outras doenças.

Alguns estudos avaliaram, em doentes com SPP, o uso de piridostigmina, imunoglobulina humana, modafinil, amantadina, hormona de crescimento e corticóides, não havendo evidência que qualquer destas substâncias confira neuroproteção ou recuperação funcional. ${ }^{9,19}$ Assim, as intervenções recomendadas têm por finalidade apenas melhorar a qualidade de vida.

Sem médico de família atribuído durante alguns anos, Silvana contou sobretudo com a médica reumatologista com quem estabeleceu uma relação de cooperação mútua. No entanto, uma avaliação multidimensional feita por médico generalista permitiu identificar necessidades da doente para além das mais imediatamente visíveis e incorporáveis no campo estreito de uma especialidade vertical e de papel complementar em situações como a da Silvana, como o é a reumatologia. Constituem disso exemplos as dificuldades financeiras determinantes da não adesão à terapêutica antiosteoporótica prescrita; a perturbação do sono; a intolerância ao frio; a catarata; a DPOC, a roncopatia e o tabagismo; o consumo excessivo de café; a vacinação; a inadaptação da habitação à incapacidade presente; a retração dos contactos sociais; e a necessidade de informação sobre a doença e sobre o tipo de exercícios recomendados.

Este caso mostra como os doentes com SPP necessitam dos cuidados de uma equipa multidisciplinar e de uma perspetiva holística. Ao médico de família, como primeiro contacto com o sistema de saúde, cabe identificar o cluster de sintomas e sinais presentes, bem como as suas repercussões psicossociais e, consoante estes, definir um plano terapêutico individualizado. Como gateskeeper cumpre-lhe mobilizar os serviços disponíveis indicados. Por assistir toda a família e pelos cuidados globais, integrados e longitudinais que presta, deve promover a funcionalidade familiar na adaptação à doença; incentivar estilos de vida adequados; ajudar a compreender a SPP, estimulando o empoderamento do doente; proporcionar suporte; avaliar continuamente a síndroma, incluindo procedimentos de case findinge, consoante os novos componentes que surjam no decorrer do tempo e os progressos conseguidos, reformular o plano terapêutico.

As repercussões e frequência da SPP justificariam a criação de grupos de entreajuda e associações específicas que proporcionassem suporte a estes doentes.

\section{AGRADECIMENTOS}

À Prof. Doutora Isabel Santos pela revisão crítica deste artigo, que se revelou imprescindível para o seu aperfeiçoamento.

\section{REFERÊNCIAS BIBLIOGRÁFICAS}

1. Halstead LS. Assessment and differential diagnosis for post-polio syndrome. Orthopedics. 1991;14(11):1209-17.

2. Dahan V, Kimoff RJ, Petrof BJ, Benedetti A, Diorio D, Trojan DA. Sleepdisordered breathing in fatigued postpoliomyelitis clinic patients. Arch Phys Med Rehabil. 2006;87(10):1352-6.

3. Oliveira AS, Quadros AA. Síndrome pós-poliomielite (SPP): orientações para profissionais de saúde [Internet]. São Paulo: Secretaria de Estado da Saúde de São Paulo; 2008. Available from: http://www.saude.sp. gov.br/resources/ses/perfil/profissional-da-saude/homepage//sindrome_pos_poliomielite_.pdf

4. Jubelt B, Cashman NR. Neurological manifestations of the post-polio syndrome. Crit Rev Neurobiol. 1987;3(3):190-220.

5. Halstead LS, Rossi CD. New problems in old polio patients: results of a survey of 539 polio survivors. Orthopedics. 1985;8(7):845-50.

6. Rowland LP, Bach JR, Borg K, Cashman NR, Dalakas MC, Dean E, et al. March of Dimes international conference on post-polio syndrome: identifying best practices in diagnosis and care. New York: March of Dimes Foundation; 2001 [cited 2015 Apr 10]. Available from: http://www. polioplace.org/sites/default/files/files/MOD-\%20ldentifying.pdf

7. Global Initiative for Chronic Obstructive Lung Disease. Global strategy for the diagnosis, management, and prevention of chronic obstructive pulmonary disease (updated 2015). London: GOLDCOPD; 2015. Available from: http://www.goldcopd.org/uploads/users/files/GOLD_ Report_2015_Apr2.pdf

8. Trojan DA, Cashman NR, Shapiro S, Tansey CM, Esdaile JM. Predictive factors for post-poliomyelitis syndrome. Arch Phys Med Rehabil. 
1994;75(7):770-7.

9. Trojan DA, Cashman NR. Post-poliomyelitis syndrome. Muscle Nerve. 2005;31(1):6-19.

10. Ragonese P, Fierro B, Salemi G, Randisi G, Buffa D, D'Amelio M, et al. Prevalence and risk factors of post-polio syndrome in a cohort of polio survivors. J Neurol Sci. 2005;236(1-2):31-5.

11. Tate DG, Forchheimer M, Kirsch N, Maynard F, Roller A. Prevalence and associated features of depression and psychological distress in polio survivors. Arch Phys Med Rehabil. 1993;74(10):1056-60.

12. YelnikA, Laffont I. The psychological aspects of polio survivors through their life experience. Ann Phys Rehabil Med. 2010;53(1):60-7.

13. Bruno RL, Frick NM. The psychology of polio as prelude to post-polio sequelae: behavior modification and psychotherapy. Orthopedics. 1991;14(11):1185-93.

14. Frick NM. Post-polio sequelae and the psychology of second disability. Orthopedics. 1985;8(7):851-3.

15. Shiri S, Gartsman I, Meiner Z, Schwartz I. Long-standing poliomyelitis and psychological health. Disabil Rehabil. 2015;37(24):2233-7.

16. Aurlein D, Strandjord RE, Helgland O. The postpolio syndrome: a critical comment to the diagnosis. Acta Neurol Scand. 1999;100(2):76-80.
17. Chan KM, Amirjani N, Sumrain M, Clarke A, Strohschein FJ. Randomized controlled trial of strength training in post-polio syndrome. Muscle Nerve. 2003;27(3):332-8.

18. Bouza C, Amate JM. Síndrome pospolio: revisión de sus características clínicas y tratamiento [Post-polio syndrome: a review of its clinical characteristics and treatment]. Rev Neurol. 2006;43(5):295-301. Spanish

19. Boyer FC, Tiffreau V, Rapin A, Laffont I, Percebois-Macadré L, Supper C, et al. Post-polio syndrome: pathophysiological hypotheses, diagnosis criteria, drug therapy. Ann Phys Rehabil Med. 2010;53(1):34-41.

\section{CONFLITO DE INTERESSES}

A autora declara não ter conflitos de interesses.

\section{ENDEREÇO PARA CORRESPONDÊNCIA}

Teresa Ventura

R. Joaquim Quirino, $6-11^{\circ} \mathrm{dt}^{\circ}$, Paço d'Arcos, 2770-089 Oeiras

E-mail: theresa.v@sapo.pt

Recebido em 01-05-2015

Aceite para publicação em 11-10-2015

\section{ABSTRACT}

\section{LATE EFFECTS OF POLIOMYELITIS: LIVING TO THE RHYTHM OF DISEASE}

Introduction: Many survivors of polio develop complications after a period of clinical stability. This case report demonstrates the need for the family physician to become familiar with the multiple facets of the late effects of polio and to recognize them as a disease entity.

Description of the case: A 69 year-old woman had polio with sequelae. Her life story showed how the struggle to overcome deficiency was central to her trajectory. Decades after the onset of the acute disease, she presented with progressive complaints of muscle weakness, fatigue, myalgia, polyarthralgia, tingling of her hands, and depression. This caused increasing functional disability, intolerance to cold, urinary incontinence, sleep disturbance, and fasciculation. Physical examination and diagnostic tests showed chronic nerve injury in the lower limbs, carpal tunnel syndrome, and various musculoskeletal disorders. Faced with new symptoms, old feelings associated with disability that she felt she had overcome, were awakened.

The treatment plan involved a multidisciplinary team. It included control of symptoms and disease progression, treating coexisting psychopathology, promotion of a healthy lifestyle, changes in her housing, prescription of assistive devices, combating isolation, mobilization of informal resources, health and social services, and transmission of information about the disease and related problems.

Comment: The late effects of polio can be minimized by following suggested guidelines. Effective management requires a doctor who can identify the characteristic cluster of signs and symptoms and their psychosocial effects and formulate an individualized treatment plan.

Keywords: Post-poliomyelitis Syndrome; Psychosocial Impact; Physicians, Family. 